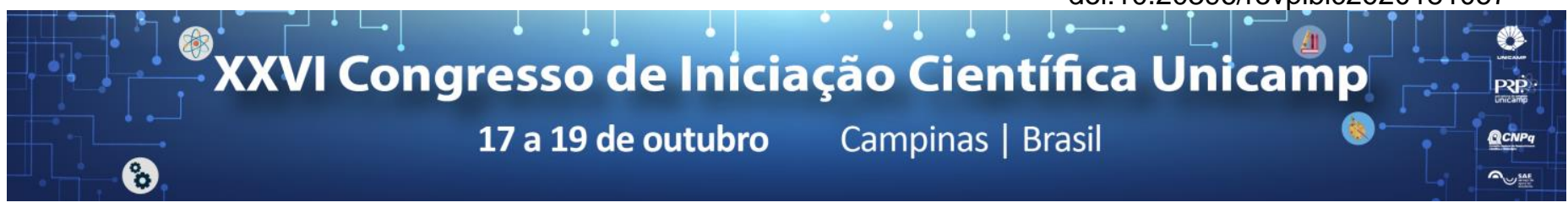

\title{
Análise da viabilidade econômica da instalação de células fotovoltaicas na Faculdade de Ciências Aplicadas da UNICAMP
}

\author{
Mirella Mariana da Boa Morte*, Ingrid Ferreira Evangelista, leda Kanashiro Makiya.
}

\begin{abstract}
Resumo
O presente projeto de iniciação científica tem por proposta analisar a viabilidade econômica da instalação de células fotovoltaicas estacionamento da Faculdade de Ciências Aplicadas na UNICAMP, Campus Limeira, tendo por base o uso do sistema bidirecional de consumo e geração de energia para a rede interna e para a concessionária de energia da cidade. Através do levantamento a respeito do consumo do local onde será aplicado o projeto, foi realizada uma comparação com os modelos utilizados para geração de energia, sob a qual levantou-se a hipótese sobre a viabilidade do uso Microgrids em relação a questões de cunho monetário para a implementação deste no ambiente escolhido.
\end{abstract}

\section{Palavras-chave:}

Smart city, Microgrid, Células Fotovoltaicas

\section{Introdução}

As smart cities, cidades com soluções inteligentes, visam reduzir custos e tempo bem como aumentar a eficácia de serviços que são de extrema importância social e econômica (ONUBR, 2017) ${ }^{1}$. Tais cidades tem por prioridade a redução e maior eficácia no uso dos recursos naturais bem como buscam a redução do consumo desenfreado (Akcin et al, 2016) ${ }^{2}$. Vislumbrando um campus com uma quantidade cada vez maior de soluções inteligentes, bem como uma redução de consumo de recursos, financeiros e naturais, o atual projeto tem por principal objetivo analisar a viabilidade dos aspectos econômicos a respeito do uso de microgrid de células fotovoltaicas no estacionamento da Faculdade de Ciências Aplicadas da UNICAMP, Campus Limeira, considerando o sistema bidirecional de consumo. Sendo assim o principal propósito deste é ampliar e reforçar o escopo de conhecimento em relação à viabilidade econômica das microgrids na região delimitada.

\section{Resultados e Discussão}

O presente estudo de caso permitiu a constatação de que com a instalação das placas fotovoltaicas em 3 fileiras do estacionamento pressupõe-se uma geração de $5150 \mathrm{kWh} /$ mês o que é capaz de suprir totalmente a demanda contratada da FCA, que é de $550 \mathrm{kWh} / \mathrm{mês,} \mathrm{e}$ gerar excedente, podendo este ser distribuído à comunidade do entorno. Para a execução desta aplicação das células foi realizado um orçamento através da ferramenta de simulação do site Portal Solar ${ }^{3}$, a qual considera a região a se instalar o sistema bem como consumo mensal em $\mathrm{kWh}$ da unidade, informando assim a quantidade de placas e a potência necessárias e a produção anual de energia do sistema.

Desta forma, para obtenção $52 \mathrm{kwp}$ de potência e para cobrir $334,14 \mathrm{~m}^{2}$, tem-se por custos:

Tabela 1: Custos de Aplicação.

\begin{tabular}{lccc}
\hline Produto & Quantidade & $\begin{array}{c}\text { Custo } \\
\text { médio }\end{array}$ & $\begin{array}{c}\text { Custo } \\
\text { Total }\end{array}$ \\
\hline $\begin{array}{l}\text { Sistema } \\
\text { gerador de } \\
\text { energia solar } \\
\text { fotovoltaica }\end{array}$ & 161 placas & $\begin{array}{c}\mathrm{R} \$ \\
175.434,00 \\
\text { até } \mathrm{R} \$\end{array}$ & $\begin{array}{c}\mathrm{R} \$ \\
208.850,00\end{array}$ \\
\hline
\end{tabular}

Fonte: Adaptado de Portal Solar (2017)

\section{Conclusões}

Proporcionar o atendimento da demanda energética da FCA e poder beneficiar seu entorno torna o projeto relevante não apenas para o campus, mas também à comunidade, gerando com isso um impacto ampliado e o cumprimento da responsabilidade social da universidade pública. Sendo assim após análise dos dados, bem como das possibilidades e impactos da implantação e custos, comprova-se a viabilidade econômica do mesmo, dependendo de parcerias tanto da iniciativa privada quanto das agências de fomento para que seja realizado.

\section{Agradecimentos}

Gostaria de agradecer à minha família por todo o apoio. A Ingrid pela parceria neste trabalho e amizade ao longo da graduação, a professora leda por todo cuidado e orientação e ao $\mathrm{CNPq}$ pelo apoio financeiro para realização desta pesquisa.

1 ORGANIZAÇÃO DAS NAÇÕES UNIDAS NO BRASIL (ONUBR). A ONU e a População Mundial. Disponível em:https://nacoesunidas.org/acao/populacao-mundial/. Acesso em: 19 de Abril de 2017.

2 AKCIN, M; KAYGUSUZ, A; KARABIBER, A; ALAGOZ, S; ALAGOZ, $B, B ; K E L E S, C$. Opportunities for energy efficiency in smart cities. Artigo.Publicação:4th International Istanbul Smart Grid Congress and Fair, ICSG 2016. Ano: 2016.

3 PORTAL SOLAR. Simulador solar. Disponível em: https://www.portalsolar.com.br/calculo-solar. Acesso em: $18 \mathrm{de}$ Outubro de 2017. 